\section{ARCHIVOS}

de historia del movimiento obrero y la izquierda
ISSN 2313-9749

ISSN en línea 2683-9601

Año IX, $n^{\circ} 17$, pp. 57-78

septiembre de 2020-febrero de 2021

\title{
Historia e historiografía del trotskismo brasileño
}

\section{Carlos Prado y Marcio Lauria Monteiro}

\author{
Universidade Federal Fluminense \\ Faculdade de Ciências Humanas da Universidade \\ Federal do Mato Grosso do Sul, Brasil \\ carlosprado1985@hotmail.com
} Universidade Federal Fluminense - Brasil
marciolmonteiro@gmail.com

Titulo: Brazilian Trotskyism's History and Historiography

Resumen: El presente trabajo da cuenta del desarrollo histórico de los primeros treinta años del trotskismo en Brasil a la vez que analiza su producción historiográfica y los principales acervos documentales existentes.

Palabras clave: trotskismo - Cuarta Internacional - Brasil - historiografia

Abstract: This text presents a synthesis of the history of the first 30 years of Trotskyism in Brazil, together with a survey on the historiographic production about Brazilian Trotskyism and its main archives.

Keywords: trotskyism - Fourth International - Brazil - historiography

Recepción: 20 de julio de 2020. Aceptación: 25 de agosto de 2020 


\section{Los primeros treinta años del trotskismo en Brasil ${ }^{1}$}

La historia del trotskismo en Brasil comenzó con la interconexión de diversos conflictos internos dentro del Partido Comunista de Brasil (PCB), fundado en 1922, con la lucha de la Oposición de Izquierda Internacional (OII). Las primeras interpretaciones sobre los orígenes del trotskismo en este país señalan que las tesis oposicionistas llegaron al país a través de la figura de Mário Pedrosa. ${ }^{2}$ A mediados de 1927 este había sido enviado a la Escuela Leninista de Moscú pero, debido a una enfermedad, permaneció en Alemania, donde tuvo contacto con la OII.

Sin embargo, investigaciones más recientes, especialmente el trabajo de Marques Neto (1993), cuestionaron esta interpretación, argumentando que diversos comunistas brasileños acompañaban las disputas producidas dentro de la URSS y la Internacional Comunista (IC). Por otro lado, más allá de las cuestiones internacionales, varios militantes "ya acumulaban diferencias políticas de fondo con el incipiente núcleo del Partido" (Marques Neto, 1993, p. 22). Así, entre los años 1928 y 1929 surgieron numerosas polémicas dentro del PCB.

La primera divergencia, planteada por Rodolpho Coutinho, ${ }^{3}$ fue sobre la táctica de la alianza con el tenentismo. ${ }^{4}$ Pero también surgieron discusiones sobre el régimen interno y la politica sindical. Estas discusiones, originadas alrededor de cuestiones nacionales pero también influenciadas por los debates internacionales, provocaron la primera escisión del PCB.

La Carta Aberta de Joaquim Barbosa, secretario sindical del parti-

1. Traducción: Lucas Duarte de Oliveira (Conicet-Cedinci), lucas.lado@gmail.com.

2. Periodista, abogado y, posteriormente, reconocido crítico de arte, se unió al PCB en 1926. Fue un importante dirigente de este partido y uno de los miembros más conocidos de la Oposición en Brasil.

3. Abogado y profesor, participó en la fundación del PCB y fue miembro suplente de su Comité Central. En 1925, fue el representante brasileño en el V Congreso de la Internacional Comunista y permaneció durante dos años en la Escuela Leninista para la formación de cuadros de Moscú. En 1928, se encontró entre los críticos del partido y acabó siendo expulsado.

4. El tenentismo fue un movimiento político y militar de jóvenes oficiales de bajo rango, tenientes y capitanes, durante la Primera República. En un escenario de creciente insatisfacción con las condiciones de las fuerzas armadas y con la política gubernamental de las oligarquías, impulsaron levantamientos militares dirigidos a implementar reformas económicas y sociales de inspiración positivista (una fuerte tradición entre los militares brasileños de entonces). El Levante dos 18 do Forte, en julio de 1922, en Copacabana, Río de Janeiro; el levantamiento de 1924, en São Paulo; y la Columna Prestes, que recorrió el interior de Brasil entre 1926 y 1928, fueron sus principales acciones. 
do, publicada en 1928, evidencia el tenor de esas divergencias. Según Barbosa, los dirigentes comunistas, al controlar diversos sindicatos, comenzaron a utilizarlos para defender intereses político-partidarios dejando a estos órganos bajo su tutela. Los primeros en oponerse a esta práctica fueron João da Costa Pimenta, trabajador gráfico y secretario de la Federação Sindical Regional de Río de Janeiro, y el propio Barbosa. Ambos renunciaron a sus posiciones y denunciaron que el partido desvirtuaba la función de los sindicatos al transformarlos en órganos partidarios.

La disputa se amplió tras la publicación de la Carta Aberta. El 2 de mayo de 1928, la dirección del PCB recibió un documento firmado por 50 militantes que presentaba una serie de divergencias, especialmente contra el régimen interno. La crítica también involucraba la política de alianzas del partido al señalar que la "pequeña burguesía militar" (el tenentismo) no podría desempeñar ningún papel revolucionario.

La petición exigía además la convocatoria a una conferencia para debatir estas cuestiones y formar una nueva dirección del partido. Sin embargo, como destacaron Dulles (1973) y Marques Neto (1993), no había cohesión entre los oposicionistas. Surgieron dos grupos: uno vinculado a Joaquim Barbosa, que mantuvo su crítica restringida a la cuestión sindical y adoptó una postura más economicista, y otro que amplió sus críticas acercándose a las tesis de la OII, especialmente mediante el contacto de alguno de sus miembros con Pedrosa.

Debido a las diferencias señaladas, estos militantes no formaron una organización inmediatamente después de romper con el PCB en 1928. No obstante, las discusiones entabladas entre ellos fueron fundamentales para el posterior surgimiento de la OII en Brasil. La escisión de ese año no fue el resultado directo de los debates soviéticos o de la toma de posición de los militantes brasileños en favor de Trotsky. Al principio, las diferencias parecen girar apenas en torno a problemas nacionales. Pero, como señalaron Marques Neto (1993) y Castro (1993), existe efectivamente una relación directa, ya que la interpretación de la teoría revolucionaria, la alianza con la pequeña burguesía y la burocratización del partido fueron temáticas que acercaron a los disidentes brasileños a las tesis oposicionistas.

Mientras estuvo en Europa, Pedrosa mantuvo contacto con el grupo oposicionista, especialmente con Livio Xavier ${ }^{5}$ y Coutinho y, de regreso en Brasil, encontrándose con un núcleo disperso y sin perspectivas de organización, trató de reunirlos. La historiografia indicó que la actuación de Pedrosa fue fundamental para que los disidentes brasileños percibie-

5. Abogado y periodista, se unió al PCB en 1927 y, al año siguiente, fue uno de los firmantes del documento que exigió democracia interna, entre otras críticas. 
ran que los conflictos en Brasil no expresaban cuestiones meramente nacionales, sino que evidenciaban una crisis mayor de los partidos comunistas, revelando el contexto internacional de degeneración burocrática. Así, a partir de la iniciativa de Pedrosa, en mayo de 1930, surgió, en la ciudad de Río de Janeiro, el Grupo Comunista Lenine (GCL).

Karepovs, Marques Neto y Löwy (1995) señalaron que la historia del movimiento trotskista brasileño, a partir de sus características y períodos, puede ser dividida en "cinco generaciones". La primera es aquella que comprende a las organizaciones formadas entre 1930 y 1939 y tiene como representantes a Pedrosa, Xavier, Coutinho, Pimenta y Aristides Lobo, ${ }^{6}$ entre otros. Vale la pena señalar que la mayor parte de las investigaciones historiográficas en el campo del trotskismo brasileño tiene como objeto de investigación estas primeras organizaciones debido a la mayor disponibilidad de fuentes y al interés por los orígenes.

Antes de resaltar algunas caracteristicas generales del GCL, es importante subrayar que la documentación sobre esta organización es bastante escasa. No se cuenta con actas, resoluciones u otros documentos que nos brinden información más precisa sobre su funcionamiento interno, sus miembros, etc. La principal fuente sobre el GCL es el periódico $A$ Luta de Classe, que versaba sobre temas táctico-estratégicos, político-ideológicos y teóricos.

De inmediato, el GCL estableció contacto con el Secretariado Provisorio de la OII y se presentó como una "fracción externa" del PCB. Destacando el contexto internacional, el GCL se reivindicó "bolchevique-leninista" presentándose como un "núcleo de resistencia a la degeneración burocrático-ideológica" de la IC. ${ }^{7}$

No obstante, como señalaron Karepovs, Marques Neto y Löwy (1995), el carácter de fracción se reveló demasiado problemático. De hecho, la organización terminó desarrollando un accionar ambiguo. Si, por un lado, los opositores terminaron presentando una política autónoma, diferenciada del PCB y por fuera del mismo; por otro lado, no convocaron a quienes permanecían en las filas comunistas al abandono del partido. Por el contrario, afirmaron la necesidad de que los descontentos permanecieran para luchar contra la dirección que se burocratizaba.

La organización del movimiento obrero y de los sindicatos fueron cuestiones centrales en la actuación del GCL. Prado (2019) argumenta

\footnotetext{
6. Profesor, ingresó en el PCB en 1923 y fue candidato a diputado por el Bloco Operário Camponês en 1928. En 1930, se exilió en Uruguay, donde mantuvo contacto con Luiz Carlos Prestes. Al regresar a Brasil, fue expulsado del PCB y se unió a la Oposición en 1931, convirtiéndose en Secretario General de la Liga Comunista, sucesora del GCL.

7. Grupo Comunista Lenine, "Nossa tática para o com o Partido", A Luta de Classe, $\mathrm{n}^{\circ} 1$, junio de 1930, Río de Janeiro, p. 1.
} 
que los oposicionistas reanudaron la polémica interna de 1928 y afirmaron que los sindicatos, como organizaciones de masas, no deberian ser sometidos a la jerarquía de un partido de vanguardia. Los sindicatos fueron entendidos como organizaciones de frente único, en los que las demandas económicas de los trabajadores deberian priorizarse por encima de cualquier interés político-partidario.

Otro aspecto importante señalado por Castro $(1993 ; 1998 ; 2000)$ es que la OII en Brasil reunió a los cuadros comunistas con mejor formación teórica. Sus principales dirigentes, Pedrosa, Xavier, Coutinho y Lobo, algunos de ellos provenientes de familias acomodadas, eran intelectuales con formación académica y dominio de idiomas extranjeros. Así, este grupo, además de trabajar en los sindicatos, contribuyó al avance del análisis de la estructura social brasileña, a partir del cual construyeron una propuesta política alternativa. En simultáneo, otra contribución fue el esfuerzo realizado en la traducción y difusión pionera de obras de Marx, Engels, Lenin y Trotsky (muchas de ellas traducidas por Xavier), publicadas por Editora Unitas (del también miembro Salvador Pintaúde).

En diciembre de 1930, ocho meses después de su fundación, el GCL ya expresaba cierto desgaste, con dificultades de comunicación y organización, como lo demuestra la correspondencia entre algunos de sus miembros. ${ }^{8}$ Se suma a ello la enfermedad y el alejamiento de Pedrosa y Xavier, lo que causó que el grupo prácticamente terminara sus actividades.

No obstante, los oposicionistas lograron superar las dificultades y reagruparse en una nueva organización. El 21 de enero de 1931 se desarrolló en San Pablo la primera reunión de la Liga Comunista - Oposición de Izquierda (LC). En comparación con el GCL, el estudio de la LC tiene la ventaja de presentar un número mucho más significativo de fuentes. Además del mayor número de ediciones de A Luta de Classe, que el grupo siguió publicando, se conservaron otros documentos, lo que permite una investigación más minuciosa sobre su estructura, accionar y debates internos.

La historiografia resaltó que una de las principales contribuciones de los trotskistas en este período fue la publicación del artículo titulado "Esbozo de análisis de la situación económica y social en Brasil". ${ }^{9}$ Del Roio (1990, p. 171) lo considera "la más consistente reflexión desde el punto de vista marxista sobre la formación social brasileña" de ese pe-

8. Carta de Mário Pedrosa a Livio Xavier, 8 de diciembre de 1930, Río de Janeiro, en Marques Neto (1993, p. 332).

9. Firmado por M. Camboa (Mário Pedrosa) y L. Lyon (Livio Xavier), "Esboço de uma análise sobre a situação brasileira", A Luta de Classe, año 2, n 6, Río de Janeiro, febrero-marzo de 1931. 
ríodo y, según Ferreira (1989), se trata de uno de los principales textos producidos por el pensamiento marxista en la década de 1930. Consistió en un análisis original del desarrollo económico brasileño desde la colonia hasta el ascenso de Getúlio Vargas.

Para Pedrosa y Xavier, la Revolución de 1930 no había representado el ascenso de la burguesía industrial por sobre los cafetaleros. A diferencia de la concepción del PCB según la cual existía un conflicto entre el campo (feudal y agrario) y la ciudad (burguesa e industrial), ${ }^{10}$ la LC analizó el golpe de Vargas como un "acuerdo general", una "última forma conciliatoria", entre las más diversas fracciones burguesas a fin de reorganizar las bases del desarrollo capitalista. Destacaron el carácter bonapartista del proceso, toda vez que la burguesía y el proletariado se mostraban incapaces de tomar el Estado y dirigirlo directamente.

La historiografia señaló que esta interpretación tuvo repercusiones en los análisis académicos. Silva (2002) destacó que la clásica interpretación de Boris Fausto, en A revolução de 1930, era bastante cercana a aquella desarrollada por los oposicionistas. Demier (2008) presentó la tesis de que el concepto de bonapartismo, desarrollado en este momento por la LC, se convirtió posteriormente en un concepto clave para la investigación de la sociedad brasileña a partir de 1930, siendo la base del concepto de populismo utilizado por Francisco Weffort y Octavio Ianni, además de haber tenido influencia también en la obra de Florestan Fernandes (militante trotskista en la década de 1940).

Frente al gobierno provisional de Vargas, la LC se posicionó en favor de la convocatoria de una Asamblea Nacional Constituyente. Autores como Castro (1993), Coggiola (2003) y Almeida (2003) enfatizaron que, a diferencia de la dirección del PCB, los oposicionistas entendian que esta lucha se presentaba como la cuestión más inmediata, ya que el gobierno de Vargas era ejercido, desde octubre de 1930, de manera discrecional. Así, veían como una tarea fundamental recuperar los derechos esenciales y defendian una Asamblea Constituyente lo más

10. La tesis fundamental, defendida por el PCB y elaborada por Octávio Brandão en 1924, esgrimía que Brasil se caracterizaba por una oposición entre los intereses de los productores de café y la burguesía industrial. De un lado, una economía agraria-feudal, basada en el latifundio y la servidumbre y, por otro, una economía urbano-industrial fundada en la producción en serie y el trabajo asalariado. Así, a partir de una interpretación dualista de la estructura económica brasileña, Brandão desarrolló una visión esquemática y etapista de la historia. La estrategia derivada de esta conclusión visaba la realización de una "revolución democrático-burguesa", para posteriormente construir el socialismo. Esta teoría es similar a la que la IC comenzó a difundir a partir del V Congreso en 1925. 
democrática posible, con plenos poderes, representación directa de los trabajadores y voto directo. ${ }^{11}$

En 1933 se produjeron cambios sustanciales motivados por el escenario internacional. El ascenso de Hitler en Alemania llevó a la OII a discutir si seguir siendo una fracción o si, por el contrario, era hora de crear nuevos partidos en la perspectiva de la construcción de una nueva Internacional. Este debate también fue librado entre los brasileños que, en acuerdo con la Conferencia Internacional, decretaron la bancarrota de la IC y del PCUS. Rebautizada Liga Comunista Internacionalista (LCI), la organización, como observan Karepovs, Marques Neto y Löwy (1995), ganó mayor autonomía y pudo presentarse como postulante a nueva dirección de la clase obrera brasileña.

Es necesario destacar que, en 1934, la LCI promovió y participó en varios frentes. Entre estas iniciativas se destacó el Frente Único Antifascista (FUA), una organización que, según Castro (1998), contó con diversas asociaciones obreras y desempeñó un papel importante en la agitación y la propaganda de combate a las fuerzas de la fascista Ação Integralista Brasileira (AIB). En el FUA los trotskistas contribuyeron con la publicación del periódico O Homem Livre, que buscaba denunciar el avance del fascismo, y participaron activamente en la contramanifestación de octubre de 1934, un episodio conocido como "Revoada dos Galinhas Verdes", en el que la acción coordinada de diversas fuerzas obreras dispersó el acto público más masivo realizado por la AIB.

En 1935 la LCI también acompañó la fundación y el desarrollo de la Aliança Nacional Libertadora (ANL) ${ }^{12}$ y presentó una serie de críticas. Almeida (2003) destaca que los trotskistas caracterizaron a la ANL como una versión brasileña de la política del frente popular, es decir, una organización que aglutinaba a todos aquellos que se opusieran al fascismo, independientemente de las posiciones político-ideológicas y el carácter de clase. Para la LCI, la ANL era una reproducción artificial del Kuomintang y un retorno a la política que culminó con el fracaso de la Revolución China. ${ }^{13}$

Durante este período, la LCI enfrentó una crisis interna debido a

11. Liga Comunista, "A palavra de ordem da constituinte", A Luta de Classe, año II, $\mathrm{n}^{\circ}$ 6, febrero-marzo de 1931, Río de Janeiro, p. 1.

12. ANL fue un frente amplio compuesto por diversos sectores y organizaciones sociales. Fundado en marzo de 1935, la organización tuvo a Luiz Carlos Prestes como presidente de honor y fue apoyada por sectores liberales burgueses y por los "tenientes" opuestos a Vargas. Su objetivo era reunir a todos los grupos contrarios al gobierno y al integralismo. De este modo, se proclamaba antifascista y antiimperialista. Sin embargo, tuvo una breve actuación legal, finalizada el 5 de julio de 1935 por la Lei de Segurança Nacional. En la clandestinidad, la ANL quedó subsumida al PCB.

13. Liga Comunista Internacionalista, "A Aliança Nacional Libertadora e a confusão 
la controversia en torno a la política de "entrismo" en el Partido Socialista francés. Entre los oposicionistas brasileños, el llamado "tournant francés" promovió acaloradas discusiones, de las cuales surgieron dos grupos: por un lado, el ala que aprobó la táctica dirigida por Mário Pedrosa, Hilcar Leite y Fúlvio Abramo. Por otro, el grupo que combatió esta política, conocido como "Fernando-Alves", que reunió a Aristides Lobo (Fernando), Víctor de Azevedo Pinheiro (Alves) y João Matheus. El grupo de Pedrosa obtuvo el apoyo del SI y culminó con la expulsión de aquellos que se reunian alrededor de Lobo. Esta escisión puso fin a un período de relativo crecimiento de la LCI, allanando el camino para su declive.

A la crisis interna se sumó el recrudecimiento de la represión estatal. A partir de los levantamientos fallidos de la ANL en Natal, Recife y Río de Janeiro, ${ }^{14}$ Vargas instauró el estado de sitio y lanzó una feroz represión. De esta manera, la LCI empezó 1936 con sus fuerzas limitadas, pero siguió actuando en la clandestinidad. En A Luta de Classe, señalaron que la pelea a partir de las fábricas y la organización de un fuerte movimiento huelguista era la única forma de resistencia capaz de "atravesar los gruesos muros de la reacción y hacerse escuchar en todo Brasil". ${ }^{15}$

La última edición de A Luta de Classe, como órgano oficial de la LCI, fue publicada en noviembre de 1936. Después de esa edición, la organización puso fin a sus actividades, pero algunos remanentes, incluidos Pedrosa, Leite y Abramo, se mantuvieron organizados y formaron el Grupo Bolchevique-Leninista (GBL). Este se fusionó con la Oposição Classista del PCB, expulsada por criticar la insurrección de la ANL. Entre sus miembros se destacan el periodista Barreto Leite Filho, el trabajador bancario Augusto Besouchet y el médico Febus Gikovate. La fusión, articulada en una cárcel, tuvo lugar el 3 de enero de 1937 en la ciudad de Río de Janeiro, creando el Partido Obrero Leninista (POL).

El documento fundador del POL, titulado "Las tareas revolucionarias del proletariado y el nuevo reagrupamiento de la vanguardia" (en Abramo y Karepovs, 2015, pp. 280-291), presentó una revaluación del escenario político-económico brasileño. Partiendo de la derrota del levantamiento de la ANL, los trotskistas señalaron sus lecciones y reafirmaron sus críticas a la actuación del PCB y a la IC burocratizada.

do movimento operário", A Luta de Classe, año V, $\mathrm{n}^{\circ}$ 25, 25 de junio de 1935, Juiz de Fora, p. 1.

14. Después de ser ilegalizada, la ANL comenzó a preparar la lucha armada para la toma del poder. Sin trabajo de propaganda en fábricas o sindicatos, apostó por el apoyo de los militares disidentes, leales a Prestes. Sin embargo, los levantamientos ocurrieron de manera apresurada siendo rápidamente reprimidos.

15. Georges [Mário Pedrosa], "A luta pelas liberdades democráticas", A Luta de Classe, $\mathrm{n}^{\circ} 1$, junio de 1936, Río de Janeiro, p. 1. 
En junio de 1937 el Comité Provisional del POL aprobó un documento que reanudaba y ampliaba la discusión sobre la estructura politico-económica nacional, firmado por Pedrosa e intitulado "La situación nacional" (en Abramo y Karepovs, 2015, pp. 292-334). En términos económicos, se llamó la atención sobre los problemas del desarrollo desigual del capitalismo en Brasil, dificultando la expansión del mercado interno, al mismo tiempo que producía un crecimiento industrial basado en la sobreexplotación del proletariado. En cuanto al escenario político, se destacó la expansión de la centralización y el papel decisivo del Estado en los países dependientes, así como la fragilidad de la democracia burguesa y el creciente avance del integralismo, configurando un "fascismo colonial".

El 10 de noviembre Vargas instauró el Estado Novo, la dictadura se consolidó y, ante la nueva oleada represiva, el POL tuvo mucha dificultad para mantener sus actividades clandestinas. Sin periodicidad, los trotskistas continuaron con la publicación de A Luta de Classe, de los Boletins de Informações Internacionais y editaron la revista Sob Nova Bandeira. Después del golpe, Pedrosa se exilió en Francia, donde participó, en 1938, del congreso de fundación de la IV Internacional, como representante de los grupos latinoamericanos siendo elegido miembro de su Comité Ejecutivo (bajo el seudónimo "Lebrun").

En Brasil, el destino del POL se vinculó a una nueva escisión en las filas del PCB que, como relatan Karepovs (2003) y Dulles (1973), experimentó una profunda crisis en ese período. Después del arresto de Prestes en marzo de 1936, el CC fue reorganizado bajo el liderazgo de Bangu (Lauro Reginaldo da Rocha) pero, durante los debates sobre las elecciones presidenciales previstas para principios de 1938, surgió un grupo opositor a partir del Comité Regional de São Paulo (CR-SP), bajo la dirección de Herminio Sacchetta.

Al igual que los trotskistas, este grupo lanzó críticas a la dirección del PCB por la orientación de apoyar la candidatura burguesa de José Américo a la presidencia (inicialmente, el candidato de Vargas). Las críticas del CR-SP también se dirigían al papel hegemónico atribuido por el PCB a la burguesía nacional en la "revolución democrática" a la que aspiraba. Sacchetta logró seguidores pero Bangu reaccionó y articuló el apoyo de importantes liderazgos regionales y de la dirección de la IC.

Una parte se reconcilió con Bangu mientras los otros fueron acusados de "fraccionalismo" y expulsados del partido en noviembre de 1937. Sacchetta y los demás separados formaron, a finales de 1937, el Comitê Pró-Reagrupamento da Vanguardia Revolucionária do Brasil. De acuerdo con Rossignoli (2018), el POL buscó acercarse a esta disidencia a través de un diálogo crítico y, gradualmente, lograron su adhesión a las tesis trotskistas. En abril de 1939 se desarrolló una pre-conferencia 
entre el POL y el grupo, que manifestó la disposición para una fusión, concretada finalmente en agosto, con la fundación del Partido Socialista Revolucionario (PSR).

En 1939, Pedrosa siguió de cerca los debates sobre la URSS en el seno de la IV Internacional. Incluso después de revelado el pacto de no agresión firmado por Hitler y Stalin, Trotsky reafirmó su posición de que era un deber de los militantes oposicionistas mantener la politica de defensa incondicional de la URSS. En desacuerdo con esta posición, Max Shachtman, miembro de la sección estadounidense y de la dirección internacional, rompió con el trotskismo. Pedrosa se posicionó a su favor y también se hizo a un lado, dejando el PSR sin contacto con la Internacional. De regreso a Brasil, trató de organizar otro grupo socialista, sin filiación trotskista, alrededor del periódico Vanguarda Socialista dentro del Partido Socialista Brasileiro (PSB).

Después de publicar algunas ediciones de A Luta de Classe, el PSR adoptó nuevos periódicos (Luta Proletária y Orientação Socialista). Centrado en São Paulo, actuó entre los trabajadores gráficos, periodistas y vidrieros. Es de destacar que la organización tuvo como uno de sus miembros al intelectual marxista Florestan Fernandes. Otra integrante reconocida fue la periodista y artista Patrícia Galvão ("Pagu"), originaria del grupo de Sacchetta en el PCB.

El PSR existió hasta los inicios de la década de 1950, cuando se disolvió, sin causas específicas claras. Se especula que se debió a divergencias en torno a las tesis "pablistas" aprobadas por el III Congreso Mundial, en 1951, y al debate en torno a la caracterización de la URSS. Parte de sus miembros, incluyendo a Sacchetta, fundó la Liga Socialista Independiente (LSI), autodenominada "luxemburguista", luego disuelta en 1961 para conformar la POLOP (Organização Revolucionária Marxista - Política Operária).

La siguiente organización que reivindicó al trotskismo en Brasil fue el Partido Operário Revolucionário (POR), fundado en 1952, por iniciativa de Guillermo Almeyra, un enviado del Buró Latinoamericano de la Cuarta Internacional (BLA, dirigido por el argentino J. Posadas), quien reagrupó a algunos ex miembros del PSR y del PSB. Tras la ruptura de Posadas con la Cuarta Internacional ("Secretariado Internacional") en 1962, el POR permaneció alineado con él y sus seguidores.

Inicialmente concentrado en São Paulo, con la publicación del periódico Frente Operária, el POR logró expandirse hacia otros estados del país a lo largo de las décadas de 1950 y 1960 y desarrollar actividades en las Fuerzas Armadas y en las zonas rurales, pero pasó por dificultades tras el golpe de 1964, dada la represión y las escisiones, perdiendo fuerza. Entre 1954 y 1963, siguiendo las orientaciones de las tesis "pablistas" del III y IV congresos mundiales de la Cuarta Internacional 
(1951 y 1954, respectivamente), esta organización realizó "entrismo" en el PCB, en el PCdoB (esta experiencia fracasó rápidamente) y en las filas nacionalistas influenciadas por Leonel Brizola. A diferencia de sus predecesores, llegó a defender el voto a un político burgués, el futuro presidente Jânio Quadros, en el momento de su candidatura para alcalde de São Paulo (1953), a pesar de haber criticado duramente el apoyo del PCB a la candidatura a la presidencia de Juscelino Kubitschek en 1950, defendiendo el voto nulo (como haría en 1960).

De las filas de este partido participaron activistas que luego serian académicos importantes como los hermanos Ruy y Boris Fausto, Leôncio Martins Rodrigues y Maria Hermínia Tavares de Almeida, además de haber sido cercanos a la organización (o bien, a algunos de sus miembros) figuras como Paul Singer, Emir Sader, Francisco Weffort, Fernando Henrique Cardoso y Octavio Ianni, algunos de los cuales participaron en el Círculo Karl Marx, un grupo de estudio organizado por el POR.

A partir de los años 1970, surgieron nuevos grupos asociados a algunas de las principales vertientes del movimiento trotskista internacional de ese momento, en particular, la Organização Socialista Internacionalista/O Trabalho (OSI/OT), Democracia Socialista (DS) y Convergência Socialista (CS). Dichas organizaciones alcanzaron, una década después, un impacto mucho mayor que sus precursoras y, a la vez, se hallan en los origenes de la mayor parte de los grupos que existen en la actualidad.

\section{La historiografía académica del trotskismo brasileño y la conservación de sus fuentes}

El GCL, la LC y la LCI son las organizaciones del trotskismo brasileño más estudiadas. También se han realizado algunos trabajos sobre el POL y el PSR pero en menor cantidad y profundidad dada la escasez de fuentes. También existe una escasa producción sobre el POR más allá de un estudio en profundidad sobre su experiencia. Sobre las organizaciones surgidas en los años 70, existe un mayor número de trabajos centrados en sus orígenes.

A la vez, se cuenta con una cierta cantidad de síntesis panorámicas, la mayoría enfocadas en los años 1920-1930 que proporcionan informaciones básicas acerca de los orígenes y las trayectorias políticas de las organizaciones, destacando sus principales miembros, sus documentos y los logros más importantes. En ellas no hay, por lo tanto, demasiada información sobre su actuación pública y su composición social o la historia de sus miembros de base.

Entre estas obras, son recomendables aquellas publicadas en la colección História do marxismo no Brasil, escritas por Dainis Karepovs y José Castilho de Marques Neto (2002), que abarcan el período 1930- 
1966 (se trata de dos de los principales especialistas en las primeras organizaciones trotskistas brasileñas) y por Karepovs y Murilo Leal (2007), cubriendo el período 1966-2000. Ambos textos se basan en la bibliografia especializada disponible hasta su publicación y en algunos de los documentos de los grupos abordados. Se trata de un punto de partida para quienes desean conocer la historia de tales grupos en lineas generales.

En la misma colección se cuenta también con una introducción a la influencia del pensamiento de León Trotsky en Brasil y a la primera generación del trotskismo brasileño, escrita por Karepovs y Marques Neto junto con Michael Löwy (1995).

Con respecto a los trabajos de investigación-académicos, los primeros en abordar el trotskismo brasileño fueron autores mayoritariamente extranjeros. Este es el caso de las obras de los años 70 escritas por los "brasilianistas" (académicos estadounidenses que investigaban temas relacionados con Brasil en la época de la dictadura militar de los años 1960-1980) John Foster Dulles (1973, basado en materiales obtenidos de Edgard Leuenroth) y Ronald Chilcote (1982 [1974]), que estudiaron el movimiento obrero y las organizaciones de la izquierda brasileña. También se encuentra el trabajo del brasileño Edgard Carone (1974, basado en materiales obtenidos de Livio Xavier), en un estilo similar. Unos años más tarde, Dulles (1985) y Carone (1985) editaron nuevos estudios basados en la documentación de Hermínio Sacchetta.

Aunque contienen información básica sobre las organizaciones trotskistas brasileñas en las décadas de 1930 y 1940, como sus orígenes y miembros destacados, no existe en ellos profundización. El foco de estos investigadores se hallaba en el PCB y en las organizaciones sindicales, por lo que los trotskistas no recibieron primordial atención.

En la década de 1970, la obra de Robert Alexander (1973) sobre el trotskismo en América Latina fue la primera que prestó mayor atención al caso brasileño. Aunque marcado por la superficialidad y el carácter esencialmente descriptivo, reveló mayor información basándose en testimonios de militantes (recopilados veinte años antes para la preparación de otro libro). Posteriormente, dicho material fue incluido en su obra sobre el movimiento trotskista internacional y, en el caso de la sección sobre Brasil, pasó por correcciones y se expandió para abarcar hasta principios de los años 80. Esta obra es, incluso en la actualidad, el estudio más extensivo sobre el movimiento trotskista internacional, aunque igualmente superficial y descriptivo (Alexander, 1991).

A finales de la década del 70 y principios de los 80, los nuevos grupos trotskistas (OT, DS y CS) publicaron, en sus periódicos, artículos y entrevistas con veteranos de las primeras organizaciones con la intención de presentarse como parte de su tradición (un listado de estos artículos 
en Karepovs, 2005, nota 27). A pesar del carácter instrumental de estos materiales, ayudaron de manera importante a recuperar la historia del trotskismo brasileño.

Años más tarde Pierre Broué escribió un artículo de síntesis sobre el trotskismo en América Latina, cubriendo hasta 1940. En él planteó algunas informaciones adicionales sobre el caso brasileño y, en particular, sobre sus orígenes. Publicado en los Cahiers Léon Trotsky $\left(\mathrm{n}^{\circ}\right.$ 11 , septiembre de 1982), fue posteriormente traducido al portugués.

Fue en los años 80, a partir del final de la dictadura, que la historia del trotskismo brasileño ganó cierto impulso en el país, a través de la publicación, como parte de la colección "Tudo é História", de Editora Brasiliense (cofundada por Caio Prado Jr.), del pequeño libro El trotskismo en América Latina, de Osvaldo Coggiola (1984), que contiene una breve sección dedicada a las organizaciones de la primera generación del trotskismo brasileño. Dos años después fue publicado, como parte de la colección "Primeiros Passos", también de Brasiliense, "¿Qué es el trotskismo?", de José Roberto Campos (1986).

Más destacada fue la colección de documentos del GCL y la LC (abarcando el período 1928-1933), publicada en 1987, también por Brasiliense, y organizada por Karepovs y un miembro fundamental de estas organizaciones, Fúlvio Abramo, titulada Na contracorrente da História. En 2015 se publicó una versión ampliada de dicha colección, incorporando textos originalmente pensados para un segundo volumen (Abramo y Karepovs, 2015). Se trata de un material importante para aquellos interesados en la primera generación del trotskismo brasileño. Además de los documentos, contiene textos introductorios de Broué (sobre el trotskismo internacional) y Abramo (sobre la Oposición de Izquierda brasileña). ${ }^{16}$

En los años siguientes, especialmente a lo largo de la década del 90, fueron desarrolladas investigaciones académicas que trataron con mayor profundidad el trotskismo brasileño. Incluso antes de la publicación de dicha colección, se produjo lo que parece ser el primer trabajo académico desarrollado por un brasileño sobre el tema, la tesis de maestría de Pedro Roberto Ferreira, defendida en 1985, en la Pontificia Universidade Católica de São Paulo, bajo la dirección de Maurício Tragtenberg, quien actuó en la LSI. Se trata de un análisis de la prensa del PSR en el período 1946-1948 (Ferreira, 1989). A pesar de la limitación del enfoque y del marco temporal, es una contribución pionera, que sigue siendo-el principal trabajo sobre esta organización.

En el pasaje de la década del 80 hacia los años 90, algunos estudios

16. Este último está disponible online, en https://www.marxists.org/portugues/ abramo/ano/mes/oposicao.htm (acceso: 26 de noviembre de 2019). 
preliminares fueron publicados por la revista Estudos del Centro de Estudos do Terceiro Mundo, de la Universidade de São Paulo (USP), dirigida por Coggiola (un listado de esos trabajos en Karepovs, 2005, nota 24).

Ya en los años 90, una serie de trabajos abordaron la Oposición de Izquierda brasileña, en gran parte a partir de los archivos de Leuenroth y Xavier. El primero fue desarrollado por Marques Neto (1993) en su doctorado en la USP, sobre la figura de Mário Pedrosa y los primeros años del trotskismo brasileño (1928-1931). Para ello utilizó documentos de las primeras organizaciones y la correspondencia de Pedrosa con otros cuadros de la primera generación, revelando mayor información a pesar de su recorte cronológico limitado. Defendida en 1992, la tesis fue publicada al año siguiente.

También en 1992, Ricardo Figueiredo de Castro defendió, en la Universidade Federal Fluminense (UFF), su tesis de maestría dedicada a la "teoría y praxis" de la Oposición de Izquierda brasileña (1928-1934). En ella utiliza algunas fuentes diferentes a las de Marques Neto y avanza más en el tiempo hasta el abandono de la condición de "fracción externa" del PCB por parte de la LC. Posteriormente, en su tesis doctoral (Castro, 1998), abordó con más detalle los análisis de la LC y la LCI acerca del fascismo en Brasil (especialmente la entonces ascendente Acción Integralista Brasileña de Plínio Salgado) y su accionar en la búsqueda de un Frente Único Antifascista.

Si los trabajos de Marques Neto y Castro enfocaron la época de la Oposición de Izquierda, Karepovs, con su tesis de maestría, defendida en 1996 en la USP, avanzó unos pasos más en la historia del trotskismo brasileño, al estudiar los embates del grupo Sacchetta al interior del PCB entre 1937-1938 (Karepovs, 2003). Más recientemente, Karepovs (2017) publicó una biografia de Pedrosa que abarca los años 1920-1980, incluyendo su período de militancia trotskista.

Aún en la década de 1990, Murilo Leal defendió, en 1997, en la USP, su tesis de maestria sobre el POR, que abarca el período 1952-1956. Basada en un análisis de extensa documentación, que incluye entrevistas con ex miembros de la organización, consiste en uno de los estudios más completos sobre una organización trotskista brasileña (Leal, 2004).

Otros dos trabajos importantes fueron producidos en la década de 1990. Por un lado, la tesis de Livre Docência ${ }^{17}$ de Alzira Lobo de Arruda Campos (Campos, 1998), presentada en la Universidade Estadual Paulista de Franca en 1998, sobre la vida de los disidentes comunistas en São Paulo entre los años 1930-1936, años formativos del

17. N.T.: Titulación posdoctoral expedida por algunas universidades brasileñas, mediante concurso público y presentación de tesis, a investigadores de reconocida trayectoria académica. 
trotskismo brasileño. A pesar de retomar el objeto de Marques Neto y Castro, trabaja con fuentes alternativas, especialmente las obtenidas en los archivos de las agencias estatales de represión de São Paulo de la época, el DEOPSISP, aunque se presentan errores resultantes de la reproducción acrítica de tales insumos. Por otro lado, la tesis de maestría de Angelo José da Silva, presentada en 1996 en la Universidade Estadual de Campinas, acerca del análisis del PCB y los trotskistas sobre el golpe que condujo a Vargas al poder en 1930 y su régimen político (libro: Silva, 2002).

En las primeras décadas del siglo XXI, la Oposición de Izquierda brasileña continuó siendo abordada a través de la tesis de maestría de Miguel Tavares de Almeida (2003) en la que se aborda el período 1930-1935, destacando la percepción de los trotskistas sobre la ANL. También de la tesis de maestría de Roberto Borges Lisboa (2014) acerca de la prensa de los grupos de los años 30, con énfasis en los análisis de la realidad brasileña y las estrategias para una revolución socialista en el país. Se destaca también la tesis doctoral de Carlos Prado (2019) acerca de los debates sobre la actividad sindical en el seno del PCB, en donde se hallan los orígenes del GCL-LC, como así también entre los trotskistas de estas organizaciones, un aspecto importante que da cuenta de la inserción de estos grupos en el proletariado.

Por lo tanto, actualmente se dispone de un rico panorama de los primeros años del trotskismo brasileño. A principios de los años 2000, una edición de la revista del archivo Edgard Leuenroth, Cadernos AEL (v. 12, n $\left.{ }^{\circ} 22-23,2005\right)$, dedicada al trotskismo, compiló parte de esta producción, contando con artículos de síntesis escritos por algunos de los investigadores mencionados anteriormente, además de un balance de la bibliografia de Trotsky disponible en portugués y un comentario sobre materiales relacionados al trotskismo brasileño archivados en el AEL.

Tal vez como un reflejo de esta acumulación ya considerable acerca de la Oposición de Izquierda brasileña y su sucesora inmediata, la LCI, en los años 2000 y 2010 comenzaron a desarrollarse los primeros trabajos académicos sobre organizaciones surgidas en los años 70. Son los casos de las tesis de maestría de Marcos Moutta de Farias (2005) sobre los orígenes de la CS, de Vitor Amorim de Angelo sobre los orígenes de DS (Angelo, 2008), y de Vinicius Almeida Ribeiro de Miranda (2014) sobre la actuación de CS y DS entre 1978-1992, al interior del Partido de los Trabajadores (PT).

Este es también el caso de la tesis de maestría de Tiago de Oliveira (2013) sobre la formación de la OSI (entre 1968-1973) y su posterior tesis doctoral acerca de cómo las nacientes organizaciones trotskistas, que luego darian origen a los grupos OT, DS y CS, analizaron el régimen 
dictatorial instalado en el país y qué líneas de actuación describieron bajo tales condiciones durante el período 1968-1973 (Oliveira, 2018).

Junto a estos estudios más amplios, se realizaron también algunos trabajos con un enfoque más específico, como la tesis de maestría de Felipe Demier (2008) acerca de la influencia del pensamiento de Trotsky sobre una parte importante de la intelectualidad brasileña, en las décadas de 1960 y 1970, como crítica a las tesis mecanicistas propagadas por el PCB sobre la realidad social del país.

Con un enfoque más específico, se dispone de la tesis de maestría de Edmar Almeida de Macedo (2011) sobre cómo la OSI y la DS abordaron los problemas de construcción de un partido político y el papel de los sindicatos. Vale la pena destacar que es uno de los pocos trabajos, además de los dedicados a la Oposición de Izquierda, en brindar mayor espacio al ámbito internacional en el que se insertó el grupo estudiado. Por su parte, se encuentra el libro de Teones França (2015) sobre el impacto del colapso del "bloque soviético" en algunos sectores de la izquierda brasileña entre los cuales se abordan, aunque brevemente, la DS y la CS.

Otros estudios sobre las organizaciones surgidas en los años 70 que ganaron fuerza en las dos décadas siguientes se encuentran actualmente en desarrollo. De modo que este periodo reciente resulta cada vez más abordado a través de investigaciones que se basan en extensa documentación, en especial los periódicos y documentos internos de los grupos en cuestión, fuentes producidas por los aparatos represivos del periodo dictatorial y testimonios orales.

No obstante, los grupos que sucedieron a la primera generación del trotskismo brasileño no quedaron excluidos pese a la menor atención recibida. En 2018 Icaro Rossignoli (2018) llevó a cabo un trabajo sobre el POL, centrado en las tácticas de reagrupamiento de la organización (que culminaron con la formación del PSR). Henrique de Bem Lignani se encuentra profundizando la deriva del PSR (Lignani, 2019).

Existen algunos trabajos más recientes que buscan un análisis regional, corriéndose del eje Rio de Janeiro - São Paulo, lo que permite una visión más ajustada de la composición y la actuación de los distintos grupos. Es el caso de la tesis de maestría de José Gallindo, presentada en la Universidade Federal de Pernambuco, acerca del accionar rural del POR en aquella provincia. Ella se enfoca en la figura de José Roberto Pinto ("Jeremias"), asesinado por latifundistas en 1963, debido a su actividad en el sindicato de los trabajadores rurales de la ciudad de Itambém, en un contexto de crecimiento de las luchas y organizaciones en el campo (Gallindo, 2013). También se cuenta con la tesis de Andreyson Silva Mariano (2011) acerca de la actuación de diferentes grupos trotskistas en la ciudad de Fortaleza, entre 1963 y 1970, utili- 
zando entrevistas y fuentes de agencias estatales de represión, además de materiales de las propias organizaciones.

Vale también mencionar la existencia de trabajos producidos en Brasil acerca de grupos de otros países, del movimiento trotskista internacional o que abordan en clave comparativa a grupos brasileños y de otros países. Es un tipo de estudio actualmente factible gracias a la disponibilidad digital de amplios y crecientes acervos de materiales del movimiento trotskista internacional y de algunos de sus "troncos históricos" más relevantes del período posterior a la Segunda Guerra Mundial.

Este es el caso de las tesis de maestría de Everardo Oliveira de Andrade (1996), sobre el POR boliviano y la revolución de 1952 en aquel país; de Isabella Meucci (2015), acerca de los debates en el interior del movimiento trotskista internacional sobre la Revolución Cubana y el foquismo y la guerra de guerrillas; de Marcio Lauria Monteiro (2016), acerca de las relecturas teórico-programáticas realizadas por los trotskistas de la posguerra ante las revoluciones sociales del período; de la tesis doctoral de Renato Fernandes (2019) acerca de la cuestión nacional en Milciades Peña; y de la investigación doctoral en curso de Lisboa, donde se realiza un análisis comparativo entre la prensa trotskista de Brasil y Estados Unidos en los años 1930 (Lisboa y Konrad, 2016).

Cabe también un último comentario sobre los acervos. ${ }^{18}$ La mayoría de las fuentes utilizadas se encuentran en el Centro de Memória Operária Mário Pedrosa (CEMAP), desde 1994 custodiado por el Centro de Documentação e Memória de la Unesp (CEDEM-Unesp). Es el caso del Archivo Livio Xavier, con muchos materiales relativos a los grupos de la primera generación y las cartas de Pedrosa. También existe una buena cantidad de material referente a la primera generación en el Arquivo Edgard Leuenroth de la Unicamp (AEL-Unicamp), recopilado por el propio Leuenroth. La documentación de Sacchetta, con material del PSR, también se encuentra en el AEL. En el Arquivo Nacional (Río de Janeiro), hay materiales de (y sobre) la LCI, el POL y el PSR, incautados (y producidos) por el Tribunal de Seguridad Nacional a partir de 1935. Periódicos y materiales internos del POR se encuentran en el CEMAP, así como las entrevistas realizadas por Leal.

En cuanto a los grupos más recientes, el archivo nacional (hasta 1994) del grupo O Trabalho se halla en el CEMAP, y existe una colección de periódicos y material iconográfico en el Centro Sérgio Buarque de Holanda (CSBH), de la Fundação Perseu Abramo, como así también material iconográfico en el AEL. El archivo nacional de la DS (hasta 2000) se encuentra en el CEMAP, y periódicos y material iconográfico en el CSBH y AEL (este también contiene documentos internos). El archivo de la CS

18. Parte de estas informaciones en Karepovs (2005) y Bianchi (2012). 
se halla en posesión del Partido Socialista de los Trabajadores Unificado (PSTU), pero está siendo puesto a disposición en línea paulatinamente a través del Archivo León Trotsky y se cuenta con publicaciones y material iconográfico en el CSBH. Parte de los periódicos de estos tres grupos también se encuentra en archivos más pequeños, como el Arquivo de Memória Operária (AMORJ) de Río de Janeiro.

Además existe material en manos de las fuerzas represivas en los archivos del Departamento de Ordem Política e Social (DOPS) y en los Archivos Públicos estaduales. Fuera del país se encuentra el archivo Alexander, en la Rutgers University (Estados Unidos), con los testimonios recopilados para sus obras.

\section{Comentarios finales}

Se puede comprobar que los estudios sobre el trotskismo brasileño crecieron considerablemente entre los años 2000 y la actualidad, después de haber comenzado, de manera tímida y superficial, en los años 70 y 80 , dando un salto fundamental en los 90 . Pese a que se ha avanzado mucho en el conocimiento histórico acerca de dicha tradición política, aún queda mucho por explorar. Como se señaló, existe una concentración desproporcionada de trabajos respecto a la primera generación del trotskismo brasileño con relación a los muy pocos escritos sobre la segunda (POL), la tercera (PSR) y la cuarta (POR). La producción acerca de la quinta generación (los grupos surgidos en los años 70 ) todavía se halla muy concentrada en el abordaje sobre sus orígenes.

De modo general, se privilegió el origen y del desarrollo político de las organizaciones, lo que, sin dudas, constituye un punto de partida importante pero es escasa la producción acerca de su composición social, actuación pública y vida interna (más allá de las cúpulas dirigentes). Es cierto que existen grandes dificultades para encontrar fuentes que permitan abordar estos temas, especialmente en relación con los grupos más antiguos, cuyos miembros ya no están vivos, pero es una parte esencial de una "historia total" de una organización política. Los pocos estudios con un enfoque regional revelan, además, otro tema importante que debe abordarse: la existencia de organizaciones fuera de los grandes centros políticos y económicos del país donde, generalmente, está el foco de sus actividades y también la mayoria de sus dirigentes.

Además, como ya se señaló, existe una seria tendencia a descuidar el ámbito internacional de estas organizaciones, que constituian una sección brasileña de una organización internacional. Más allá de que no se pueda reducir el grupo nacional a la organización internacional a la que pertenece, es innegable que ella posee un peso considerable sobre sus elaboraciones estratégicas e incluso tácticas, especialmente en el 
período posterior a la Segunda Guerra cuando la Cuarta Internacional atravesó una creciente fragmentación teórico-programática.

Debido a la complejidad de producir una "historia total" del trotskismo brasileño, es imprescindible la actuación en conjunto de los investigadores dedicados a dicho objeto. La existencia de un espacio conjunto para debates y colaboración, la realización de eventos académicos y la elaboración de colecciones contribuiría en gran medida al avance de esta producción historiográfica. De forma modesta, los autores de este artículo se vienen involucrando en algunas iniciativas en ese sentido, en particular la organización de mesas temáticas como parte de los Coloquios Internacionais Marx e o Marxismo (celebrados cada dos años en la UFF), dedicados a la historia del trotskismo. Esperamos que este artículo sirva como estímulo para nuevas investigaciones y colaboraciones.

\section{Bibliografia}

Abramo, F. y Karepovs, D. (2015), Na contracorrente da História. Documentos do trotskismo brasileiro (1930-1940), 2a ed., Sundermann.

Alexander, R. (1973). Trotskyism in Latin America. Hoover Institution Press.

Alexander, R. (1991). International trotskyism, 1929-1985: A Documented Analysis of the Movement. Duke University Press.

Almeida, M.T. de (2003). Liga Comunista Internacionalista. Teoria e Prática do Trotskismo no Brasil (1930-1935). Disertación (Maestría en Ciencias Sociales), Pontificia Universidade Católica de São Paulo.

Andrade, E.O. de (1996). O Partido Obrero Revolucionario e a revolução boliviana de 1952. Disertación (Maestría en Historia Económica), Universidade de São Paulo.

Angelo, V.A. (2008). A trajetória da Democracia Socialista: da fundação ao $P T$. EdUFSCar.

Bianchi, Á. (2012). É possível escrever a história recente dos trotskismos brasileiros? Perseu, v. 8, pp. 361-380.

Campos, A.L. de A. (1998), "Tempos de viver": dissidentes comunistas em São Paulo (1931-1935). Tesis (Livre-docência), Universidade Estadual Paulista.

Campos, J.R. (1986). O que é trotskismo. Nova Cultural-Brasiliense.

Carone, E. (1974). A República Nova: 1930-1937. DIFEL.

Carone, E. (1985). A República liberal, 2 v. DIFEL.

Castro, R.F. de (1993). A oposição de esquerda brasileira (1928-1934): teoria e práxis. Disertación (Maestría en Historia). Universidade Federal Fluminense.

Castro, R.F. de (1998). Contra a guerra ou contra o fascismo? As esquerdas brasileiras e o antifascismo, 1933-1935. Tesis (Doctorado en Historia), Universidade Federal Fluminense.

Castro, R.F. de (2000). Os intelectuais trotskistas nos anos 30. En D.A. 
Reis filho (org.). Intelectuais, história e politica: séculos XIX e XX. Letras, pp. 137-152.

Chilcote, R.H. (1982). Partido Comunista Brasileiro: Conflito e integração, 1922-1972 [1974]. Graal.

Coggiola, O. (1984). O trotskismo na América Latina. Brasiliense.

Coggiola, O. (2003). Trotskyism in Brazil (1928-1964). Disponible en https:// www.marxists.org/history/etol/document/brazil/brazilo1.htm.

Del Roio, M. (1990). A classe operária na revolução burguesa. A politica de alianças do PCB: 1928-1935. Oficina do Livro.

Demier, F. (2008). Do movimento operário para universidade: León Trotsky e os estudos sobre o populismo brasileiro. Disertación (Maestría en Historia Social). Universidade Federal Fluminense.

Dulles, J.F. (1973). Anarquistas e comunistas no Brasil: 1900-1935. Nova Fronteira.

Dulles, J.F. (1985). O comunismo no Brasil: repressão em meio ao cataclismo mundial. Nova Fronteira.

Farias, M.M. (2005). Partido socialista ou Partido dos Trabalhadores? Contribuição à história do Trotskismo no Brasil: a experiência do Movimento Convergência Socialista. Disertación (Maestría en Historia Comparada). Universidade Federal do Rio de Janeiro.

Fernandes, R.C.F. (2019). As trajetórias da dependência argentina: a questão nacional em Milcíades Peña. Tesis (Doctorado en Ciencia Política). Unicamp.

Ferreira, P.R. (1989). Imprensa, politica e ideologia: Orientação Socialista (1946-1948). Mores.

França, T. (2015). Escombros do Muro de Berlim sobre a esquerda brasileira. MaudX.

Gallindo, J.F.R. (2013). Jeremias. O trotskismo no campo em Pernambuco. UFPE.

Karepovs, D. (2003). Luta subterrânea: O PCB em 1937-1938. Hucitec-Editora da UNESP.

Karepovs, D. (2005). O arquivo Edgard Leuenroth e a pesquisa sobre o trotskismo no Brasil. Cadernos AEL, v. 12, n. 22-23.

Karepovs, D. (2017). Pas de politique Mariô! Mário Pedrosa e politica. Ateliê.

Karepovs, D., y Leal, M. (2007). Os trotskismos no Brasil: 1966-2000. Reis Filho, D.A. y Ridenti, M. (orgs.). História do marxismo no Brasil, v. 6, UNICAMP, pp. 153-238.

Karepovs, D., y Marques Neto, J.C. (2002). Os trotskistas brasileiros e suas organizações políticas (1930 - 1966).Reis Filho, D.A. y Ridenti, M. (orgs.). História do marxismo no Brasil, v. 5, Editora da UNICAMP.

Karepovs, D., Marques Neto, J.C., y Löwy, M. (1995). “Trotsky e o Brasil”. Quartim de Moraes, J. (org.), História do marxismo no Brasil, v. 2, Editora da Unicamp, pp. 229-254.

Leal, M. (2004). A esquerda da esquerda: Trotskistas, comunistas e populistas no Brasil contemporâneo (1952-1966). Paz e Terra. 
Lignani, H.B. (2019). O trotskismo brasileiro e a construção do partido revolucionário: as experiências do POL e do PSR (1937-1945). Anais do Colóquio Internacional Marx e o Marxismo 2019, Marxismo sem tabus enfrentando opressões, Niterói (http://www.niepmarx.blog.br/MM2019/ Trabalhos\%20aprovados/MC4/MC42.pdf).

Lisboa, R.B. (2014). Revolução e realidade social na imprensa trotskista brasileira dos anos 1930. Disertación (Maestría en Historia). Universidade Federal de Santa Maria.

Lisboa, R.B., y Konrad, G.V.R (2016). Trabalho, Sociedade e Marxismo: Uma abordagem relacional do trotskismo brasileiro e estadunidense dos anos 1930. Anais do XVI Encontro Estadual de História da ANPUH-SC: História e Movimentos Sociais, Chapecó, pp. 1-12 (http://www.encontro2016. sc.anpuh.org/resources/anais/43/1464645156_ARQUIVO_ArtigoRobertoEEHSC.pdf).

Macedo, E.A. de (2011). Os trotskistas entre discursos e controvérsias. Tradição, composição social e alinhamento internacional. Disertación (Maestría en Sociología). Universidade Federal do Paraná.

Mariano, A.S. (2011). Uma esquerda em silêncio. Militantes trotiskistas de Fortaleza no periodo de 1963-1970. Disertación (Maestría en Historia). Universidade Estadual do Ceará.

Marques Neto, J.C. (1993). Solidão revolucionária: Mário Pedrosa e as origens do trotskismo no Brasil. Paz e Terra.

Meucci, I.D.P. (2015). A Revolução Cubana e o movimento trotskista na América Latina: impactos na construção de um projeto politico (1959-1974). Disertación (Maestría en Ciencia Política). Unicamp.

Miranda, V.A.R. de (2014). Dois trotskismos num partido de massas: as trajetórias das organizações Democracia Socialista e Convergência Socialista no PT de 1978 a 1992. Disertación (Maestría en Ciencia Política). Universidade Estadual de Campinas.

Monteiro, M.L. (2016). O movimento trotskista internacional e as revoluções do pós-guerra: uma análise de suas (re)leituras teóricas e programáticas (1944-63). Disertación (Maestría en Historia Social). Universidade Federal Fluminense.

Oliveira, T. de (2013). Reorganização do movimento trotskista no Brasil. A formação da Organização Socialista Internacionalista (1968-1976). Um capítulo da IV Internacional no Brasil. Uma contribuição à história do trotskismo no Brasil. Disertación (Maestría en Historia Social). Universidade Federal Fluminense.

Oliveira, T. de (2018). Trotskistas na ditadura militar (1968-1973), uma contribuição à História do Trotskismo no Brasil. Tesis (Doctorado en Historia Social), Universidade Federal Fluminense.

Prado, C. (2019). Partidos e sindicatos: o PCB, a Oposição de Esquerda e o movimento operário no Brasil (1922-1936). Tesis (Doctorado en Historia), Universidade Federal Fluminense.

Rossignoli, I. (2018). Os dias de cão do trotskismo brasileiro: argumentos e 
táticas nas publicações do Partido Operário Leninista, 1937-1939. Tesina de Graduación en Historia, Universidade Federal do Rio de Janeiro.

Silva, A.J. da (2002). Comunistas e trotskistas: a crítica operária à revolução de 1930. Moinho do Verbo. 